\title{
Research on Knowledge Sharing and Transfer in Remanu- facturing Engineering Management Based on SECI Model
}

\begin{abstract}
In this paper, an application mode and method of knowledge management in remanufacturing engineering management is established based on Nonaka's SECI model. The relationships between knowledge transfer, knowledge sharing and remanufacturing engineering management are highlighted. It is noticeable that a great deal of knowledge transfer and sharing activities, which can improve the performance of remanufacturing engineering management constantly, are involved in remanufacturing engineering.
\end{abstract}

Keywords: remanufacturing, engineering management, knowledge transfer and sharing, knowledge management

\section{Introduction}

As a new direction developing in the 21 st century in China, remanufacturing engineering has the characteristics of resource conserving, energy saving and environmental protection, which highly meets the national strategic needs of building circular economy and provides key technical support for that. To vigorously develop the circular economy is one of the main ways to achieve energy conservation and sustainable development (Xu \& Zhu, 1999). Remanufacturing engineering technologies can restore the technical performance of the original products, introduce new technologies, new processes and new materials, improve the technical performance and reliability of the products, and upgrade the system, hence extending the life of the product. The costs of remanu-

Manuscript received January 29, 2016; accepted April 10, 2016

Ling-ling Zhang (凶)

School of Economics and Management, University of Chinese Academy of Sciences, Beijing 100190, China; Key Laboratory of Big Data Mining and Knowledge Management, Chinese Academy of Sciences, Beijing 100190, China

Email: zhangll@ucas.ac.cn

Ming-hui Zhao, Qiao Wang

School of Economics and Management, University of Chinese Academy of Sciences, Beijing 100190, China factured products are only $40 \%-60 \%$ the costs of the newly manufactured products. Therefore, remanufacturing has gained widespread attention. However, there is no unanimously accepted definition of remanufacturing currently. Professor Robert Lund T., who is a remanufacturing research pioneer in America, discussed the definition in 1984: remanufacturing is restoring durable goods in an economical way, after disassembling, clean checking, repair processing, re-assembling, and adjusting the test of the whole production process (Lund, 1984). In China, it is defined as: remanufacturing is a series of technical measures or engineering activities, which are guided by product life cycle design and management to achieve high quality, high-efficiency, energy conservation, material saving and environmental protection. It uses advanced technologies and industrial production as a means to repair or modify the general waste products. The object of remanufacturing-"product" is a generalized concept. It can be equipment, systems, facilities, and its components, including hardware and software (Hu, Wang, \& Xu, 2001).

Because a lot of knowledge is generated in the production process, remanufacturing engineering is a typical knowledge-intensive industry. There are a lot of activities related to knowledge transfer and sharing in remanufacturing engineering management. Knowledge transfer and sharing is also a key element in knowledge management. How to manage the related knowledge in the process of remanufacturing engineering management and realize knowledge sharing within the enterprise, even within the entire remanufacturing industry is particularly urgent. The research of Knowledge Management (KM) began in the early 1980s. Dr. Sveiby first proposed the concept of knowledge-based enterprises and knowledge management in 1986. The Socialization-ExternalizationCombination-Internalization (SECI) model of knowledge flow proposed by Nonaka and Takeuchi, which describes the distinction of explicit knowledge and tacit knowledge, established the foundation for future research of knowledge management (Nonaka, 1994).

With the development of the new technology revolution and the emergence of new management theories and methods, the problems in remanufacturing engineering 
could be solved more efficiently. This paper tries to combine knowledge management and the key processes of remanufacturing engineering management, and to focus on the research of knowledge transfer and sharing in remanufacturing engineering management. This research provides insights into the knowledge transfer and sharing activities in the remanufacturing enterprises and improves the efficiency of knowledge transfer and sharing in remanufacturing engineering management, thus increasing the competitiveness of enterprises. Moreover, the application of knowledge management in remanufacturing engineering management is also an extension of the theory of knowledge management.

\section{Literature review}

\subsection{Remanufacturing engineering management}

There have been many studies in the field of remanufacturing. Most studies are about logistics, the characteristics of organization and process and the technical characteristics. Remanufacturing mainly includes three parts: remanufacturing processing, outdated product performance upgrades and structural upgrades. The general steps of remanufacturing products are as follows: the complete disassembly of the product, cleaning of parts, inspection and classification of parts, readjusting or replacing the product, and reassembly (Liu \& Wang, 2004). Ehrenfeld established a logical network representation model (based on the relationship between product components) for product disassembly, and proposed an algorithm for generating the optimal disassembly path to achieve maximum recovery efficiency of products (Ehrenfeld, 1995). Wang proposed a disassembly model based on Petri network to analyze the economical efficiency of disassembly and to generate the optimal disassembly path (Wang, B. \& Wang, N., 2000). Wang and Tao discussed the current mainstream remanufacturing technologies, such as surface technology, bonding technology, the "blank" remanufacturing forming and reprocessing technology, and rapid prototyping technology in the early 1980s (Wang \& Tao, 2000). Lund reviewed literatures in the field of remanufacturing, including selection of products, marketing strategy, remanufacturing technology, cost analysis, institutional factors and legal matters (Lund, 1984). Guide and Srivastava made an indepth analysis of the impact that the uncertainty of recycling may bring to production flow and proposed some solutions relevant to the logistics and production control (Guide \& Srivastava, 1997). Guide, Kraus and Srivastava analyzed the features of the production process, but not the different effects of production objects, processes, and technology (Guide, Kraus, \& Srivastava, 1997). Remanufacturing industry is new in China, but it has been developing rapidly because of Xu's efforts $(\mathrm{Xu}$,
1996). The surface engineering technology proposed by Xu has provided the technical support for China's remanufacturing industry. In 2002, the national defense key laboratory of equipment remanufacturing technology was established. The developed research field describes the first outline of remanufacturing research, which represents the mainstream of remanufacturing research in China (Zhu, 2001). Remanufacturing industry is promising in China. The research on key innovative technology of remanufacturing is mature overseas, but the domestic remanufacturing industry is still in its preliminary stage. The lack of remanufacturing industrial management system hinders the wide application of remanufacturing technology and the healthy development of remanufacturing industry, and it has become one of the bottlenecks of the development of remanufacturing industry in China (Xu, Zhu, \& Ma, 2003). The management issues, such as remanufacturing risk management, remanufacturing production management, quality management, certification and accreditation, and performance appraisal, are main topics in remanufacturing research (Xu, Shi, Liu, \& Zhou, 2012).

2.2 The combination of knowledge management and remanufacturing engineering management

The research on the relationship between remanufacturing management and knowledge management in China is still in its early stage. The research of knowledge management in traditional manufacturing industry has been greatly developed, but there are few studies on knowledge management in the field of remanufacturing. Pan, Wang and Liu gave the basic process of applying knowledge management in manufacturing enterprises, after they analyzed the problems of knowledge demand and knowledge structure during the implementation of knowledge management in an aviation manufacturing enterprise (Pan, Wang, \& Liu, 2007). Hu defined knowledge management from the perspective of information management based on the influence of knowledge management on information process of manufacturing enterprises and designed innovative solutions for problems in manufacturing enterprises. The security system for implementing information management innovation project in enterprises is also proposed ( $\mathrm{Hu}, 2006)$. Zhao analyzed the relationship between risk management and knowledge demand of remanufacturing system and put forward knowledge demand chain to improve the risk management level of remanufacturing system. Through the analysis on the process of remanufacturing practice, he identified six knowledge gaps in the process of risk management implementation, and built remanufacturing risk management model based on knowledge management (Zhao, 2011). Consider the characteristics of product and manufacturing process, Yang and Rao combined process knowledge classification principles and methods and established a classification of remanufactur- 
ing process knowledge. He explored the possibility of developing a product remanufacturing knowledge management system based on Browser / server three-layer network architecture using the dynamic server page technology (Yang \& Rao, 2008). Luo managed decommissioning engineering machinery products and conducted green evaluation research of remanufacturing process on the basis of traceability information (Luo, 2014).

The research on knowledge management of remanufacturing enterprises is mainly aimed to help enterprises to manage knowledge and information using systematic methods, and to help the enterprises to adapt to the new environment. Rowley studied knowledge organization methods and retrieval matching form based on Web environment for network enterprises (Rowley, 2001).

Ha, Pahng, Chang, Park and Rho proposed the management approaches to design knowledge, and developed the corresponding software system named active document system (ADS) (Ha, Pahng, Chang, Park, \& Rho, 1999). Thannhuber, Tseng and Bullinger studied knowledge management in manufacturing enterprises and proposed a method called 'Autopoetic,' which is similar to the biologic evolution theory that knowledge is evolved through a number of evolutionary changes (Thannhuber, Tseng, \& Bullinger, 2001).

\section{Relationship between remanufacturing management and knowledge management}

Remanufacturing is a process of recovering worn durable products to usable and economical state by disassembling and decomposition, cleaning and checking, rebuilding and reprocessing, reassembling, testing and adjusting. The whole life cycle of the product includes five parts: demonstration and design, manufacture, use, maintenance and scrap. Remanufacturing is a kind of regeneration process of product maintenance and scrap. The main process of remanufacturing is shown in Figure 1.

Knowledge management theory has enriched the under- standing of remanufacturing engineering management. Nonaka's knowledge creation theory has provided a new perspective for remanufacturing engineering management. Nonaka's model has 4 kinds of knowledge creation modes, including socialization, externalization, combination and Internalization (see Figure 2) (Nonaka, 1994). These four modes constantly interact with and convert to each other, giving rise to knowledge transfer, knowledge sharing, and knowledge creation.

If knowledge management is applied to the process of remanufacturing engineering management, the performance of remanufacturing management will be improved. The combination of remanufacturing engineering management and knowledge management can form a virtuous cycle of improvement and development to achieve high performance of the organization.

\section{Knowledge transfer and sharing in rema- nufacturing based on SECI model}

Remanufacturing is an industrial process. In this process, scrap products will be restored to new products. Through a series of industrial processes in the industrial environment, scrapped products are completely disintegrated. The disintegrated parts are gathered in the warehouse after cleaning and repair while new components are added as needed, and then new products are assembled using the old parts and new components and they are strictly tested in accordance with the new product technical requirements for new products. Qualified remanufactured products will on the market in accordance with the requirements of new products. Five main links (shown in Figure 3) in remanufacturing can combine SECI model with knowledge transfer, sharing, and creation in enterprises. The remanufacturing engineering management also supports the knowledge transfer and sharing process. The relationship between the SECI model and the enterprise quality management activities is shown in Table 1 .

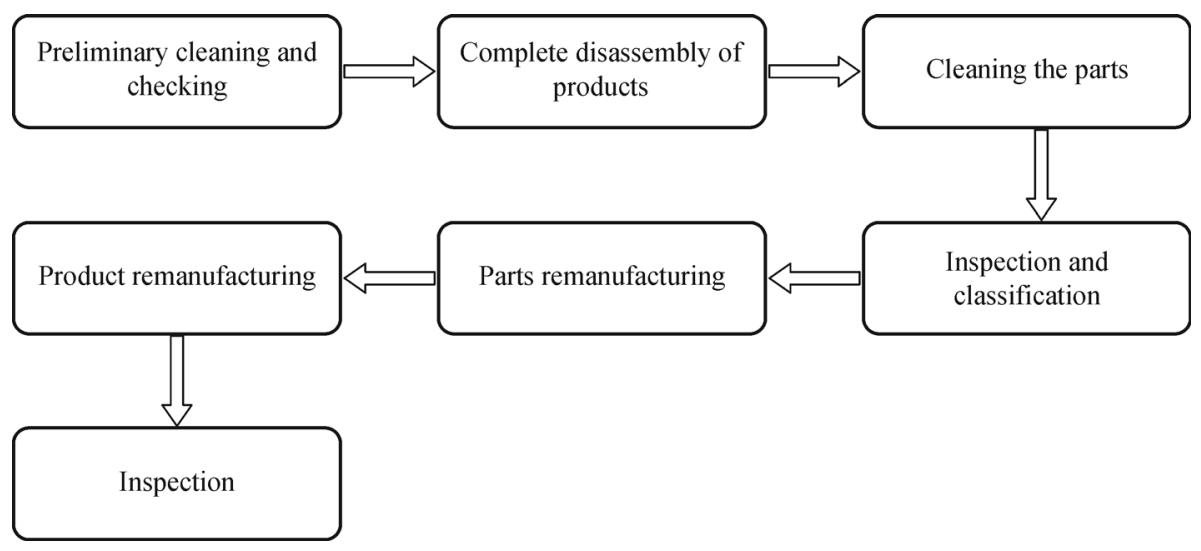

Figure 1. The main process of remanufacturing. 


\begin{tabular}{|c|c|c|}
\hline & Tacit knowledge & Explicit knowledge \\
\hline Tacit knowledge & Socialization & Externalization \\
\hline Explicit knowledge & Internalization & Combination \\
\hline
\end{tabular}

Figure 2. SECI process.
4.1 The disassembly and inspection process of the product

Preliminary cleaning and testing of the parts require some information, such as the appearance, types, manufacturing time of the parts. These data will be stored in the database of the company. Components are completely disassembled. Low value parts and parts that requires mandatory replacement are removed. All the remaining parts, after thorough cleaning, need to be evaluated to determine the extent of damage and detailed renovation plan is given

Table 1

The Relationship between Remanufacturing Management and Knowledge Management

\begin{tabular}{|c|c|c|c|c|}
\hline \multirow{2}{*}{$\begin{array}{l}\text { Key points in remanufacturing } \\
\text { engineering } \\
\text { management }\end{array}$} & \multicolumn{4}{|c|}{ Corresponding forms of SECI model } \\
\hline & $\begin{array}{l}\text { Socialization } \\
\text { Tacit-Tacit }\end{array}$ & $\begin{array}{l}\text { Externalization } \\
\text { Tacit-Explicit }\end{array}$ & $\begin{array}{c}\text { Combination } \\
\text { Explicit-Explicit }\end{array}$ & $\begin{array}{l}\text { Internalization } \\
\text { Explicit-Tacit }\end{array}$ \\
\hline $\begin{array}{l}\text { Product receiving, } \\
\text { preliminary cleaning and } \\
\text { inspection }\end{array}$ & $\begin{array}{c}\text { Face to face communication } \\
\text { between clients and } \\
\text { inspectors }\end{array}$ & $\begin{array}{l}\text { Generate communication reports } \\
\text { and cleaning \&inspection records }\end{array}$ & $\begin{array}{l}\text { Generate product's demand } \\
\text { reports and } \\
\text { inspection regulations }\end{array}$ & $\begin{array}{l}\text { Generate demand } \\
\text { check list, and train } \\
\text { inspectors }\end{array}$ \\
\hline $\begin{array}{l}\text { Complete disassembly and } \\
\text { cleaning of products }\end{array}$ & $\begin{array}{c}\text { Face to face communication } \\
\text { between disassembly and cleaning } \\
\text { stuff }\end{array}$ & $\begin{array}{l}\text { Generate complete disassembly } \\
\text { and cleaning proposals }\end{array}$ & $\begin{array}{l}\text { Generate complete disassem- } \\
\text { bly and cleaning schemes of } \\
\text { products }\end{array}$ & $\begin{array}{c}\text { Generate product } \\
\text { check list, and train } \\
\text { disassembly and } \\
\text { cleaning stuff }\end{array}$ \\
\hline Checking and sorting & $\begin{array}{l}\text { Face to face communication } \\
\text { between checking and sorting stuff }\end{array}$ & $\begin{array}{l}\text { Generate checking and sorting } \\
\text { records }\end{array}$ & $\begin{array}{l}\text { Generate checking and sorting } \\
\text { standards and regulations }\end{array}$ & $\begin{array}{l}\text { Train checking and } \\
\text { sorting stuff }\end{array}$ \\
\hline $\begin{array}{l}\text { Parts remanufacturing and } \\
\text { warehousing }\end{array}$ & $\begin{array}{l}\text { Face to face communication } \\
\text { between remanufacturing and } \\
\text { warehousing stuff }\end{array}$ & $\begin{array}{l}\text { Generate production records } \\
\text { and warehouse records }\end{array}$ & $\begin{array}{l}\text { Generate operational stan- } \\
\text { dards for production \& opera- } \\
\text { tion \& warehousing }\end{array}$ & $\begin{array}{l}\text { Train remanufacturing } \\
\text { and warehousing stuff }\end{array}$ \\
\hline Equipment testing and delivery & $\begin{array}{l}\text { Face to face communication } \\
\text { between stuff of test warehouse }\end{array}$ & $\begin{array}{l}\text { Generate inspection reports, } \\
\text { testing records, and warehouse } \\
\text { records }\end{array}$ & $\begin{array}{c}\text { Generate data analysis reports } \\
\text { and packing operation } \\
\text { instructions }\end{array}$ & $\begin{array}{l}\text { Generate product } \\
\text { check list, and train } \\
\text { testing stuff }\end{array}$ \\
\hline
\end{tabular}

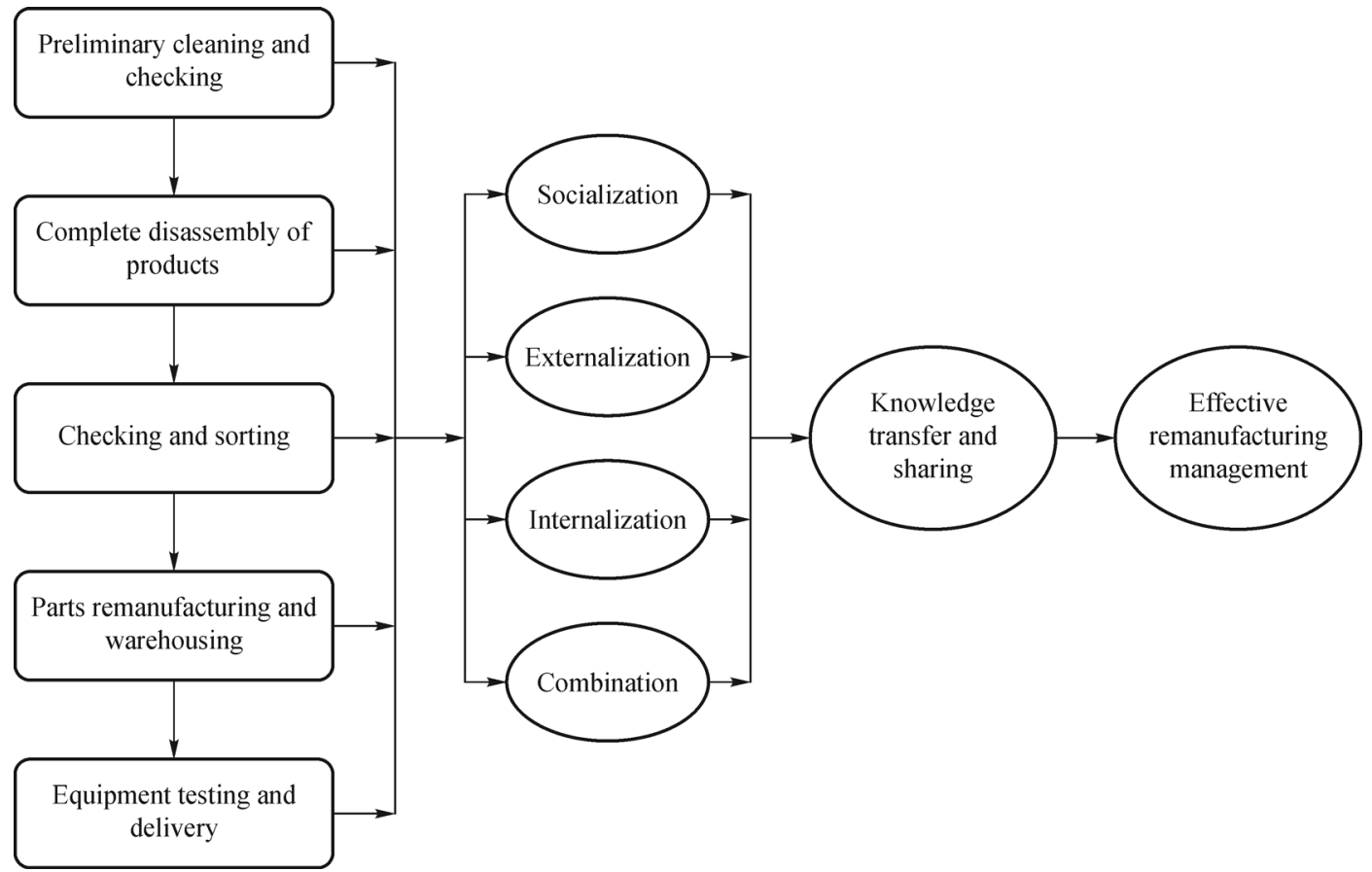

Figure 3. The application mode of knowledge management (based on SECI model) in remanufacturing management. 
according to the examination results. Based on the organizational knowledge creation model (SECI), Nonaka and Takeuchi proposed a comprehensive five-stage model of organizational knowledge creation (Figure 4) (see Nonaka \& Takeuchi, 1995). In remanufacturing engineering management, the five-stage model is a typical model of knowledge transfer and sharing in the processes of product disassembly, inspection, design and development. In the product disassembly and inspection activities, the remanufacturing production enterprises will set up a special team, including function members of inspection, cleaning, disassembly, inspection and classification, to transfer and share knowledge, and to effectively improve the quality of remanufacturing engineering products.

(1) The disassembly inspection process of the product and socialization

The disassembly inspection process of a product starts from the sharing of tacit knowledge. A typical approach is to build a team to capture knowledge and ideas. For example, the American Boeing 707 set up more than 200 designing and manufacturing teams to collaborate, rather than use the traditional labor division. Effective research and development teams encourage members to actively participate and interact with each other (Tesluk \& Mathieu, 1999). This requires the understanding of the team's development process, and team working spirit can enable members to communicate conveniently and understand each other. Management theory also supports the importance of teamwork and employee involvement (Hoegl \& Gemuenden, 2001). At each stage of product disassembly inspection, there will be a review activity and the participants should include all the functional representatives of the manufacturing phase. In the disassembly inspection activities, the organization encourages a wide range of interaction among the members, which realizes the socialization process and achieves the sharing of tacit knowledge among individuals. For example, the American HP Company established a culture of knowledge sharing and an environment for tacit knowledge transfer. The whole company promotes a culture of mutual cooperation and knowledge sharing, advocates the spirit of adventure and even encourages employees to try some innovations that may have no results. In the design and development phases, the knowledge transfer and sharing are very important. Appropriate development organizations (such as a project team or a virtual team) and a culture of development, collaboration and trust can be built to set up reasonable incentive measures. All these will contribute to the realization of knowledge transfer and sharing, which aims to guarantee and improve the quality of the products.

(2) The disassembly inspection process of the product and externalization

In the process of product disassembly and inspection, the team first implements disassembly and checking using the following tools: brainstorming method (Charnes \& Gitlow, 1995) and affinity diagram. Mizuno pointed out that some tools can help left brain thinking (intelligence, analysis, evaluation and language skills), other tools such as affinity diagram can help right brain thinking (emotional, comprehensive, mood changes, non-verbal ability). Right brain

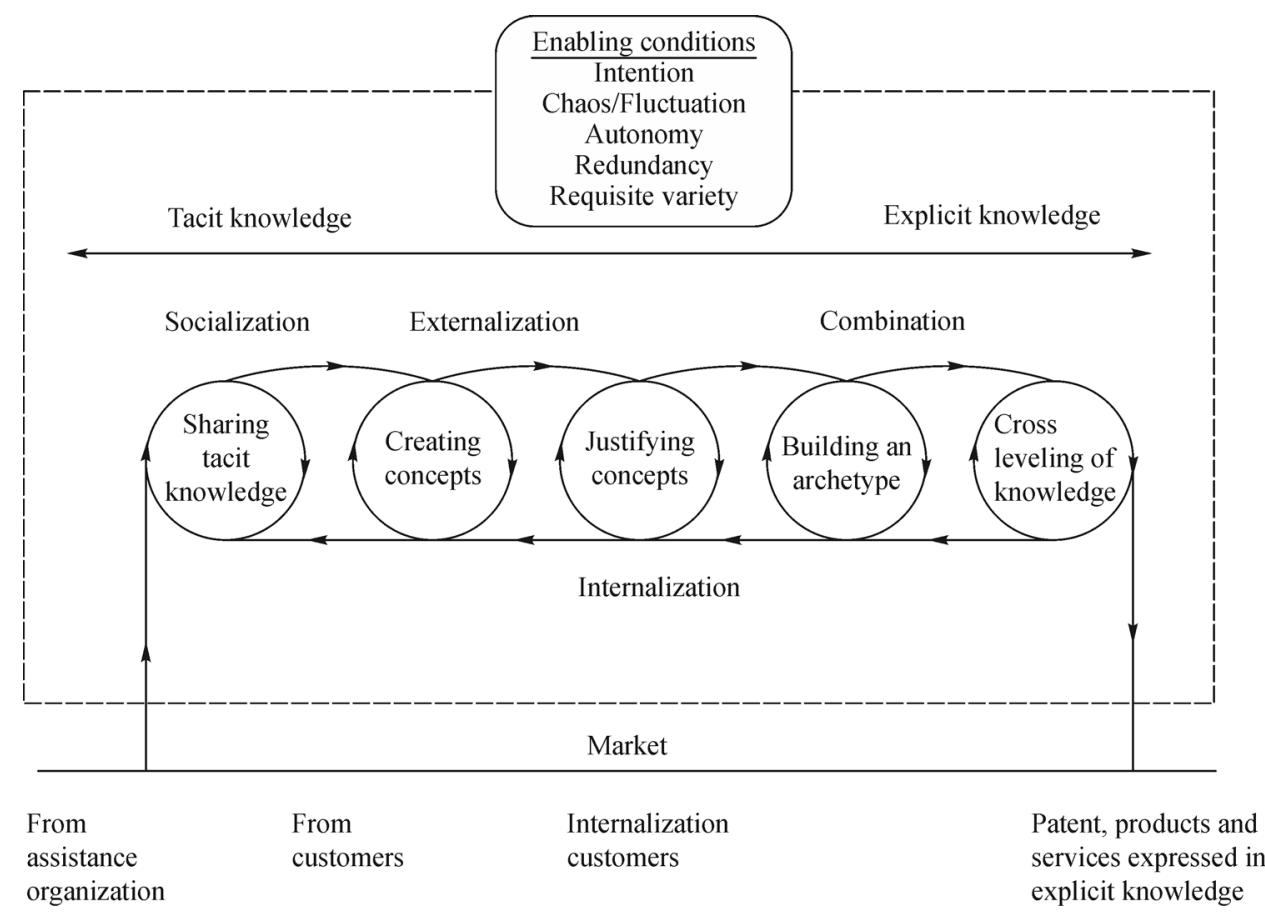

Figure 4. Five-phase model of the organizational knowledge-creation process. 
thinking is similar to the tacit knowledge according to Nonaka. This kind of knowledge is difficult to encode. Therefore, the use of the aforementioned tools can help capture the tacit knowledge of individuals, and then the knowledge can be externalized by proposals and concepts. The organization encourages the free airing of views and uses "right brain" tools to ensure the realization of externalization in the disassembly and inspection activities. For example, when Canon was developing the small copiers, how to produce a cheap and replaceable cartridge is a major problem for the research team. One day, after drinking some beer, the leader asked: "what is the cost to produce these cans?" The leader expressed his tacit knowledge in this way. Inspired by this, the research team began to study the probability to produce a cartridge with the production process of cans. Then a technique of producing aluminum cartridge with very low costs was invented.

Cause and effect analysis should be used in the management of remanufacturing engineering, so that tacit knowledge can be expressed in the form of concept or theory. Ming Dai advocated the development theory in the profound knowledge system. Drucker also believed that this theory can improve the enterprise performance. Reasonable understanding of the organization should be developed outside the organization, and it helps to create tacit ideas in the organization. Organizations express recommendations of disassembly and inspection by means of theory, concept or cause and effect, and then improve the degree of externalization.

(3) The disassembly inspection process of the product and combination

This part requires that the members of the disassembly and inspection process in the manufacturing process to create new knowledge through explicit knowledge. The use of data analysis tools will be beneficial for combination. During the disassembly and inspection processes, the enterprise can solve problems by taking extensive information analysis to encourage the combination.

(4) The disassembly inspection process of the product and internalization

In the disassembly and inspection teams, after three processes of socialization, externalization and combination, the experiences become valuable assets. For example, all the members of "Honda City" project development team of the Japanese company Honda internalized their experience, and then lead other design and development projects using these tips (Nonaka \& Takeuchi, 1995). After a series of disassembly, cleaning, checking and sorting activities, the output are generally drawings, standard documents, manuals, standards, patents and software, which are important knowledge assets of the enterprises. These documents facilitate the transfer of explicit knowledge to others, which will help other members of the enterprise to experience and to learn and enrich the tacit knowledge of the individual.

\subsection{The remanufacturing process of the parts}

All parts and related parts are processed to meet the technical requirements. This stage may involve surface treatment (e.g. repairing parts affected by corrosion), and mechanical and electrical processes (e.g. metal spraying or welding to restore worn parts). After the normal mechanical and electrical performance test, the remanufactured parts with attached labels will be placed into the warehouse. Parts to be replaced also need to be ordered from the original manufacturers or from other remanufacturing enterprises (including the enterprise). The manufacturing process involves many links. If the knowledge transfer and sharing are fully carried out, it will be helpful to improve the production efficiency and improve the quality of products. Making effective incentive measures and constructing the appropriate situation can improve the efficiency of knowledge transfer and sharing in the manufacturing process.

(1) The remanufacturing process of parts and socialization

In the remanufacturing production process, enterprises should encourage the production staff to make full contact with each other. Effective teams work together to bring various skills, knowledge and abilities (Stevens \& Campion, 1994). For example, the iron and steel enterprises organize experience exchange meetings to assist employees to communicate with each other about work experience. These experiences, including how to improve the work efficiency, how to design hot metal transportation routes, and what are the most comfortable gesture for employees to take at work, are tacit knowledge. These experiences are promoted after verification in the organization to establish standards and form a corporate knowledge. This process helps members to share tacit knowledge and socialize with each other. Enterprises should encourage members to interact with each other, which will help them understand the production process and promote socialization.

(2) The remanufacturing process of parts and externalization

Generally speaking, tacit knowledge is more valuable than explicit knowledge. The ability of mining and using tacit knowledge will become the key to the success of individuals and organizations. Through the use of code, metaphor, analogy and model, the valuable tacit knowledge will be transferred into explicit knowledge for convenient spreading. For example, experienced steelmaking furnace craftsmen demonstrated the relationship among temperature, oxygen blow amount and the rate of good products through the process of trial and error experiments and repeated demonstration within the organization until the members agree with the experimental experience consensus. A software program was finally developed to automatically control temperature and oxygen blowing amount. The process of transformation from experience to 
universal software programs which is widely used in many workshops is a process of externalizing tacit knowledge.

(3) Parts remanufacturing process and combination

In remanufacturing production process, the production staff combines different kinds of explicit knowledge through many media such as process documents, work instructions, meetings, telephone conversations or computer networks. By arranging for, adding, combining and classifying explicit knowledge related with the production process, and restructuring existing information, new valuable knowledge will be created. Process control is the basis of controlling the quality of production in manufacturing enterprises. Enterprises should formulate basic working technical programs of process control according to the production features. It means that enterprises should determine process monitoring points based on systematic research, process capability analysis and statistical process control method. For processes that are not consistent with the quality requirements, the variance analysis should be conducted to identify the sources of variation. The sources of variance should be analyzed to find out the reasons. Then the processes and methods can be optimized to reduce process variability, stabilize and improve the quality of the production process. This allows the members in organizations to create new knowledge based on a variety of different information. Thus, monitoring the production process can be beneficial for combination and can help to generate new knowledge.

(4) The remanufacturing process of parts and internalization

Internalization is a process of converting explicit knowledge to tacit knowledge, which is essentially a learning process (Zhang, Wang, \& Jiang, 2005). In the remanufacturing production process of parts, the production staff can receive the team and enterprise knowledge continuously by reading a variety of quality documents (such as process documents, operation instructions, quality inspection standards and quality reports), participating in various training and $\mathrm{QC}$ teams, and to improve the mental models, skills and techniques. For example, Motorola encoded operating knowledge into documentation manuals and training materials by Lotus Notes, so that employees can have free access to these documents in the company's internal public network. Through "online learning," the transformation from "explicit knowledge" to individual "tacit knowledge" is promoted. Motorola tries to encourage employees to share personal knowledge with other employees through a variety of ways, namely "tacit knowledge" to "explicit knowledge" transfer, and then "explicit knowledge" to the staff"s own "tacit knowledge" transfer through studying to improve the employee's knowledge and skills. In China, the Little Swan Company permeated the "wholeheartedly Little Swan" quality innovation and operation mechanism to the whole process of development, production, sale and service. The objective is to seek "zero dead angle" for quality and service. As a result, this enterprise gained good reputation in both domestic and international markets, and realized the technology export and the internationalization of the product market.

\section{Conclusions}

In this paper, the key processes of remanufacturing engineering management and Nonaka's SECI model are combined to explore the relationship between main processes of remanufacturing engineering management and knowledge transfer and sharing. Based on the SECI knowledge management model, application models and methods of remanufacturing engineering management are proposed. The process of remanufacturing engineering management is a process of knowledge transfer and sharing. Enterprises can gain more knowledge through the remanufacturing engineering management activities, and knowledge transfer and sharing also improve remanufacturing engineering management.

Acknowledgements The authors gratefully thank the anonymous reviewers for their constructive feedback. This work was partially supported by National Natural Science Foundation of China (Grant No. 71471169 and Grant No. 71071151).

\section{References}

Charnes, J.M., \& Gitlow, H.S. (1995). Using control charts to corroborate bribery in jai alai. American Statistician, 49, 386-389.

Guide, V.D.R., Kraus, M.E., \& Srivastava, R. (1997). Scheduling policies for remanufacturing. International Journal of Production Economics, 48, 187-204.

Guide, V.D.R. Jr, \& Srivastava, R. (1997). An evaluation of order release strategies in a remanufacturing environment. Computers \& Operations Research, 24, 37-47.

Ha, S., Pahng, G., Chang, M., Park, S., \& Rho, H.M. (1999). Managing design knowledge: active document system. CIRP Annals-Manufacturing Technology, 48, 89-92.

Hoegl, M., \& Gemuenden, H.G. (2001). Teamwork quality and the success of innovative projects: a theoretical concept and empirical evidence. Organization Science, 12, 435-449.

Hu, G., Wang, S., \& Xu, B. (2001). The engineering of green remanufacture and its application prospect in China. Water Conservancy \& Electric Power Machinery, 23, 33-35.

$\mathrm{Hu}$, X. (2006). Research on enterprise information management innovation for manufacturing enterprises based on knowledge management. Journal of Modern Information, 12.

Ehrenfeld, J.R. (1995). Design for environment: a new framework for strategic decisions. Environmental Quality Management, 4, 37-51.

Liu, Z., \& Wang, J. (2004). Discussion on remanufacturing engineering. Construction Machinery \& Maintenance, 12, 135-136.

Lund, R.T. (1984). Remanufacturing: the experience of the USA and 
implications for the developing countries. In Heggie, I. (Eds.), World Bank Technical Papers (pp. 31). New York: World Bank Publications.

Luo, J. (2014). Study on green performance assessment of retired construction machinery remanufacturing process based on information tracing (Master's thesis). Changsha: Hunan University.

Nonaka, I. (1994). A dynamic theory of organizational knowledge creation. Organization Science, 5, 14-37.

Nonaka, I., \& Takeuchi, H. (1995). The knowledge creating company: how Japanese companies create the dynamics of innovation. New York: Oxford University Press.

Pan, X., Wang, J., \& Liu, L. (2007). Research on knowledge management in manufacturing enterprise. Science Research Management, 28, 160-166.

Rowley, J. (2001). Knowledge organization in a web-based environment. Management Decision, 39, 355-361.

Stevens, M.J., \& Campion, M.A. (1994). The knowledge, skill, and ability requirements for teamwork: Implications for human resource management. Journal of Management, 20, 503-530.

Tesluk, P.E., \& Mathieu, J.E. (1999). Overcoming roadblocks to effectiveness: Incorporating management of performance barriers into models of work group effectiveness. Journal of Applied Psychology, 84, 200-217.

Thannhuber, M., Tseng, M.M., \& Bullinger, H.J. (2001). An autopoietic approach for building knowledge management systems in manufacturing enterprises. CIRP Annals-Manufacturing Technology, 50, $313-$ 318.
Wang, B., \& Wang, N. (2003). Research on disassembly model based on Petri Net for a product. Journal of East China Shipbuilding Institute Natural Science Edition, 17, 87-90.

Wang, R., \& Tao, Y. (2000). Discussion on the re-manufacture technology. Journal of Hefei University of Technology, 23, 11-13.

Xu, B. (1996). Surface engineering and maintenance. Beijing: Beijing Machinery Industry Press.

Xu, B., Shi, P., Liu, B., \& Zhou, X. (2012). Engineering management problems of remanufacturing industry. China Surface Engineering, $25,107-111$.

Xu, B., \& Zhu, S. (1999). Advanced remanufacturing technologies based on nano-surface engineering. Retrieved from Proc. 3rd Int. Conf. on Advances in Production Eng, 35-43.

$\mathrm{Xu}$, B., Zhu, S., \& Ma, S. (2003). Construct and development of equipment remanufacture engineering specialty. China Surface Engineering, 16, 1-6.

Yang, H., \& Rao, X. (2008). Research and development to the management system of remanufacture process knowledge. Equipment Manufacturing Technology, 3.

Zhang, H., Wang, K., \& Jiang, Z. (2005). Study on reform collective Forestry's property relations in China. Chinese Agricultural Science Bulletin, 21(2).

Zhao, Q. (2011). Study on risk managerial mode for remanufacturing system based on knowledge management. Heavy Machinery, 6.

Zhu, S. (2001). Study on the connotation and scientific structure of green remanufacturing engineering. China Surface Engineering, 14, 5-11. 